\title{
HEALTH AND SAFETY MANAGEMENT ON CONSTRUCTION PROJECTS: THE VIEW OF CONSTRUCTION TRADESPEOPLE
}

\author{
Emmanuel Eze ${ }^{1 *}$, Onyinye Sofolahan ${ }^{2}$, Lawrence Siunoje $^{3}$ \\ ${ }^{1}$ Quantity Surveying Department, Federal University of Technology, Owerri, Imo State-Nigeria \\ ${ }^{2}$ Quantity Surveying Department, Lagos State Polytechnic, Nigeria \\ ${ }^{3}$ Building Technology Department, Delta State Polytechnic, Ozoro, Nigeria
}

(Received: October 2020 / Revised: October 2020/ Accepted: November 2020)

\begin{abstract}
The complex networks of activities of construction projects have made the construction environment unfriendly and unsafe for the construction tradespeople. Tradespeople play a key role in construction project delivery and are the major victims of accidents that affect negatively on project performance. This study assessed the perception of construction tradespeople on the health and safety management on the construction site. The study objectives are; to determine the trade with the highest accident exposure level, to ascertain the types of accidents and level of occurrence, to determine the major causes of accidents on construction sites, and to examine the possible measures for preventing accidents on construction sites. A well-structured questionnaire and stratified purposive sampling technique were adopted in gathering data from the participants in Abuja, Nigeria. With a reliability index of at least 0.80 , the gathered data were analysed using frequencies, percentiles, mean analytics, Kruskal-Wallis test, and Mann-Whitney U tests. The study found that Concreters/Mason/Bricklayers, Carpenters, and Steel benders/fixers/welders are the most vulnerable trades groups to hazards and accidents on construction sites. Fall-related, Slip and trip, and contact with objects (struck by objects) are the most occurring accident types. The most critical causes of accidents based on tradespeople perception are; inadequate training, drugs and alcohol, horseplay by workers, excessive working hours resulting in mental fatigue, and communication issues. The most important measures for preventing accidents on construction sites are; rewards and penalties for defaulters, the use of personal protective equipment, effective communication system on-site, correct placement of ladder through proper supervision, and site discipline among workers. The study concludes that there is a low level of implementation of health and safety management practices on construction projects site by construction organisations. Rewards for safety compliances and penalties for HS deviant workers should be put in place by the management of construction sites.
\end{abstract}

Keywords: Accidents; Construction Project; Health and Safety; Nigeria; Tradespeople

\section{INTRODUCTION}

The construction industry is among the top industries of any nation that contribute greatly to the survival and sustenance of economic and infrastructural development. The rapid development of construction activities derives from the economic development of any nation (Tanko et al., 2020).

*Corresponding author's email: emmanuel.eze@futo.edu.ng, Tel. +234-806 4237041

DOI: https://doi.org/10.32783/csid-jid.v3i2.165 
Eze et al. (2017) described the industry as the economic prime mover and the bedrock of the survival of economies. Despite the immense importance of the industry in bringing about rapid growth and development, its activities have been confirmed to contribute to a very high level of accidents and fatality relative to other industries (Chen et al., 2020).

The industry has a long-standing poor performance record of health and safety. This has been blamed on the complexity, multiple stakeholders, dynamic operational environment, and organisational arrangements of construction projects, which have regularly resulted in accidents and injuries to workers (Chen et al., 2020). Odeyinka et al. (2006) submitted that hazards and risk control has been made more difficult due to the frequent dynamics in technology, construction techniques, construction materials, clients' demands, and work environment. Health and safety issues on construction sites are a global problem (Zhou et al., 2013), and this has given rise to poor project time, cost, and quality performance, with numerous claims and disputes. The occurrence of accidents could lead to a temporary stoppage of work, which could result in delays, damage to finished work, an increase in operating cost, and quality issues.

Like other developing countries of the world, the Nigerian construction industry is dominated by $78 \%$ indigenous small and medium-sized construction organisations (Tunji-Olayeni et al., 2018). These firms are predisposed to several forces both from their external and internal environments. The influence of these forces is more on the SMEs because of their characteristics and management style, which make them suffer higher HS deviance practices when compared to the large and mostly foreign multi-national construction organisations. The health and safety performance of construction organisations in the construction industry of Nigeria is poor. This is evident in the submission of Okoye (2018). It was posited that in Nigeria, construction tradespeople are still being exposed to injuries, disease, and fatalities. In spite of the level of technological advancement and level of professionalism in the construction industries in this $21 \mathrm{st}$ century. Similarly, Williams (2019) confirmed that the spate of accidents and fatalities occurrences is still high in Nigeria. Furthermore, Umeokafor et al.(2014) found that HS provisions and conventions are poorly implemented, and Idoro (2008) accentuates that there is the absence of policies approved for HS in the construction industry of Nigeria. These make health and safety to be left to the hands of contractors and their employees, who are constantly being under pressure to deliver at the expense of their safety in a hazard-laden environment and conditions. According to the submission of Udo et al. (2016), construction activities are carried out in the open and exposed atmosphere. In addition, Khosravi et al. (2014) submitted that construction workers discharge their assignments in an unsafe and unhealthy environment which could result in a decline in productivity.

There are a lot of extant studies on health and safety on construction projects that sampled construction professionals, consultants, clients, or contractors (Abas et al., 2020; Agyekum et al., 2018; Belayutham \& Ibrahim, 2019; Chen et al., 2020; Mohammed et al., 2015; Williams et al., 2019). While only a limited number of them sampled construction tradespeople (artisans, craftsmen, operatives), who are the set of workers carrying out the actual building production work (Kukoyi \& Smallwood, 2017; Okoye, 2018; Tanko et al., 2020). Kukoyi \& Smallwood (2017) carried out a qualitative study of Health and Safety (H\&S) Construction Practices in Lagos. The study explored the perceptions of mainly production workers (ironworkers, masons, carpenters, roofers, and electricians) engaged in construction projects regarding $\mathrm{H} \& \mathrm{~S}$ on construction sites. The study reported that productive activities on construction sites as hazardous and risky, and there is a lack of understanding of the use of PPE. This study which took place in Lagos only sampled 5 participants and sample questions covered H\&S training, risk awareness, use of PPE, and employee and management interactions as regards H\&S. Okoye (2018) assessed 
the occupational Health and Safety Risk Levels of Building Construction Trades in Nigeria. The study used simple random sampling and focused on identifying the sources, frequency, and magnitude of risks inherent in the activities of various building construction trades within the Anambra state. The study found that the level of occurrence, magnitude, and impact of the safety risk factors differs across building trades. While this study is limited a state, it types of accidents and measures for preventing accident on site were ignored in the sampling. In Malaysia, Tanko et al. (2020) adopted a mixed-method research approach in investigating compliance with the Use of Personal Protective Equipment (PPE) on Construction Sites in Johor. The study, which focused only on PPE compliance found that, there is a high awareness but low compliance level of the use of PPE by construction workers in the study area.

The majority of these studies ignored the construction tradespeople who are the most critical sitebased workers that are often the victims of safety failures. The limited number of studies that sampled construction tradespeople on HS related issues was carried out in a different region or states in Nigeria. Furthermore, there are limited studies that have sampled construction tradespeople on HS practices in the study area of this present study. It is based on these that this study assesses the perception of construction tradespeople on the health and safety management on the construction site. The main objectives of this study are; 1$)$ to determine the trade with the highest accident exposure level, 2) to ascertain the types of accidents and level of occurrence, 3) to determine the major causes of accidents on construction site, and 4) to examine the possible measures for preventing accidents on construction sites. The proper HS management practices on construction sites entail identification of the causes of accidents, proffering possible solutions to preventing or minimising their occurrences; so that the work environment will be safe and healthy for the site workers. Knowing the major causes of accidents and the exposure level of construction site workers will help in their assessment and responses in terms of eliminating them. This would lead to an improvement in the health and safety performance of construction projects. Aghimien et al. (2019) submitted that Health and safety issue are among the components of the social dimension of sustainable construction project delivery. Thus, this study contributes to the social dimension of sustainability and complements the environmental and economic dimensions of sustainable construction.

\section{LITERATURE REVIEW}

\subsection{Construction Tradespeople and Accident Exposure}

In the context of this study, construction tradespeople include craftsmen, artisans, and other site operatives that are different from the built environment professional and experts. Tradespeople are workers with trade specialisations where work experience requires training on the job; due to modernization and to avoid gender bias, it is more fashionable to use the term 'tradespeople' (Ugulu et al., 2019). They include skilled carpenters, masons, plumbers, plasterers, painters, and glaziers. Eze et al. (2017) submitted that construction artisans, craftsmen, or operatives are the categories of construction field workers that are physically and directly involved in the execution of the works and production of the finished buildings and other construction-related structures. This set of workers forms the main construction site workers that are commonly engaged by all categories of construction organisations. Thus, the productivity of construction projects and the performance of construction organisations are dependent on the tradespeople. Construction tradespeople are very essential in the delivery of construction projects be it civil and/or building projects. This is because their inputs in the installations and assembly of building materials and components have an impact on the time, cost, and quality of the final product (Afolabi et al., 2018). 
These trade workers are constantly being exposed to various degrees of hazards and fatalities due to the nature of the work they do and their level of involvement. However, some are more exposed to HS challenges than the others; because the content of the risk of every worker's assignment differs from trade to trade. Construction tradespeople work in teams or groups and are made of skilled, semi-skilled, and labourers with varying degrees of experience on the job and awareness level of health and safety-related matters. Labourers were found to be more exposed to accidents than skilled carpenters, masons, and plant operators (Alinaitwe et al., 2007). In an earlier study, steel/ironworkers and roofers were the building trades with the highest exposure to health and safety risks (Baradan \& Usmen, 2006). In the USA, Choi (2015) reported that the trade groups with the highest susceptibility to construction site hazards and accidents are labourers, carpenters, steel/ironworkers, and operators. Workers, whose tasks involve lifting, like the masons and their labourers (helpers) are exposed to injuries like musculoskeletal injuries/disorders (Ray et al., 2015). Lifting entails, manual material handling activities and these have a serious impact on the muscles and skeletal posture of the workers. One of the trades with the highest accident rate in the construction industry is masonry as reported by (Schneider \& Susi, 1994).

The vulnerability of the construction tradespeople to accidents and injury and other site hazards is a reflection of their level of involvement in the delivery of construction works. Understanding the trades with the highest accident-prone rate and the likely causes is vital in the HS planning and control and management of fatalities on site. Szóstak (2019) states that construction works are executed throughout the whole calendar year usually under variable atmospheric conditions. These works are done during the day, evening, and night times. Some construction workers are made to work overtime beyond the normal eight-hour day; thus, with such conditions, workers are exposed to high health and safety risks. Furthermore, according to Szóstak (2019), Construction workers in the case of accidents play three roles (these are; the decision-maker, the perpetrator of an accident, and the victim).

\subsection{Accidents Types and Causes on Construction Sites}

The construction industry experiences a frequent level of accidents, and this according to Zou et al. (2007), has been blamed on job pressures, long construction periods, hazardous machine operations, complex processes, work environment being hazardous. Bell and Healey (2006) reported that the major causes of accidents are consist of poor management practices (i.e. inadequate supervision), the pressure to meet production targets, inadequate safety management systems, failure to learn lessons from previous incidents, communication issues (i.e. between shifts, between personnel and management), inadequate reporting systems, complacency, violations/ non-compliance behaviour, inadequate training (i.e. in areas of emergency responses, fire, and safety), lack of competency, excessive working hours resulting in mental fatigue, inadequate procedures, modification/ updates to equipment without operator knowledge and/or revised risk assessments, inadequate maintenance of tools and equipment, and maintenance errors.

Arunkumar and Gunasekaran (2018) grouped the major causes of accidents into five groups and they are; unsafe act, unsafe working condition, communication barrier, management commitment, and training. The possible factors responsible for the accidents are failure to follow safety rules, ignorance of PPE (Personal Protective Equipment), space congestion, improper use of safety items, and improper equipment.

The Perecman Firm (2014) posits that on the construction site, the 'fatal four' causes of accidents and fatalities are falls, struck by objects, electrocution, and caught-in between. Furthermore, these 'fatal four' causes 3 out of 5 construction workers' deaths. Other common accidents on-site include 
slip and fall, ladder accidents, scaffolding accidents, power tool, and machinery accidents, musculoskeletal disorders, and vehicle accidents. However, workers' attitudes and behaviours contribute to the occurrence of accidents on sites. Many fatalities have been blamed on negligence, unsafe worksite conditions, absence of protective safeguards, and abuse or poor handling of tools and/or equipment. Similarly, Williams et al. (2019) found that the most occurring accident type is contact with working tools, vehicle-related, slip and trip, and falls. Williams et al. (2019) further reported that the major causes of accidents are; failure of edge protection, safety standard violations, overloading of scaffold and crane, wrong placement of ladder, loss of control over body movement, failure in the designs, absence of warning signs, over speeding of vehicle, wrong selection of working tools, non-usage of personal protective equipment, improperly installed equipment, horseplay, and poor housekeeping.

HG.org Legal resources (2020) identified the common causes of fatalities on construction sites to include; Slip and falls which is caused by unsafe working conditions, falling on stairwells caused by incorrect installation or absence of handrails, Stepladders which can tip over or even collapse, Falls from roofs caused by lack of fall protection, failure to obey safety regulations for scaffolding.; which can easily collapse, Collapsing of trenches and excavation faces due to nonuse of supports, power tool accidents in situations where the eye and ear protection were neglected, improper lifting with back muscles instead of legs, and dump trucks, forklifts, and other vehicles.

Certain conditions reduce the efficiency of site operations and predispose them to hazards and accidents. Yusof and Misnan (2019) revealed that these variable are poor occupational Safety and Health (OSH) management, financial constraint, lack of training and knowledge on safety management, high competition, lack of communication, unsatisfactory safety motivation, poor safety culture, inefficient safety person in charge and time pressure.

\subsection{Measures for improving HS management practices on construction sites}

According to Kirwan (1998), Safety management has to do with actual practices, roles, and functions that are connected with remaining safe. It is usually carried out through an organisation's safety management system with the support of different safety management practices (Agyekum et al., 2018). The design of the safety management practices differs from country to country because of the cultural differences in the construction industries of both developed and developing (Ali et al., 2009; Ismail et al., 2012). Choudhry et al. (2008) posit that for a company to remain competitive, it must implement safety practices that meet the dynamic needs of the construction industry. According to Choudhry et al. (2008), The benefits of implementing good safety management practices are: Reducing the number of injuries to personnel and operatives in the workplace through the prevention and control of workplace hazards; minimizing the risk of major accidents; controlling workplace risks improve employee morale and enhances productivity; minimizing production interruptions and reducing material and equipment damage; reducing the cost of insurance as well as the cost of employee absences; minimizing legal costs of accident litigation, fines, reducing expenditures on emergency supplies; and reducing accident investigation time, supervisors' time diverted, clerical efforts, and the loss of expertise and experiences. Construction and client organisations are thus, required to implement good safety management practices in order to enjoy the full benefits inherent in safety health and environment.

Construction projects are complex with a lot of stakeholders and parties. There is different types of machinery, equipment, tools, trucks, materials, and various categories of workers that are working currently. The movement of these materials, equipment, and people is some time without 
a pattern, thus, exposing humans, materials and the building components to various degrees of hazards. Even though there is a high exposure level of workers to fatalities, there a possible measure for minimizing the injuries on construction sites, and these involve all hands being on deck for it to succeed.

Every stakeholder and party to a construction contract has a role to play in terms of ensuring that HS is taken seriously on site. Safety is everybody's business when it comes to construction contracts and other developmental projects. The project clients have a critical role to play, they stand on top of the hierarchy for bringing the needed change to issues relating to the safety of workers, equipment, materials, and the building being executed. Lingard and Blismas (2013) posit that client is in the most suitable position to initiate the cultural change required to ensure safety improvement. This is because clients take the major decisions that would make or mar safety implementation and adherence on site. Construction projects because of the need to meet project quality specifications and schedule, could compromise quality and this could result to rework and an increase in construction costs. It is the role of the client to ensure and acknowledge that safety plays a complementary role in quality and schedule, which consequently leads to a decrease in construction costs (Sunindijo, 2015). Thus, the clients need a comprehensive safety intervention. This includes ensuring that only contractors with proven safety performance records are awarded projects during the procurement phase.

Health and safety training and induction programmes for new employees are one of the ways to endure effective safety performance of construction contractors. Sunindijo (2015) submitted that the cost of training and compliance is a major impediment, especially to SMEs because of their limited financial strength and economic forces. HS training and induction programmes can improve safety consciousness and performance of construction site operatives. To ensure sustainable safety training in construction organisations, Sunindijo (2015) advocated for safety training incentives and supports. Companies with existing training programmes need to be assessed for effectiveness and to ensure that the practices are not neglected.

HS improvement strategies identified by Belayutham and Ibrahim (2019) include; safety being considered as criteria during tendering, construction organisations should provide a suitable platform for exchanges of knowledge and experiences that will promote best practices, funding of OHS training to be taken over by the government, making safety one of the Key Performance Indicators, strict enforcement of safety regulation, creating more safety-conscious culture, rewards, and penalties for defaulters, effective communication system on-site, and health and safety training programmes. Hasle and Limborg (2006) opined that the government should effectively monitor and ensure the enforcement of safety regulations by organisations. Enforcement of safety regulations will go a very long way in ensuring the safety of construction workers and reduced accidents and other health hazards.

In the Eswatini Construction Industry, Aghimien et al. (2019) revealed that the creation and implementation of HS plans, proper workers welfare, and government and client support are the key drivers of HS management practices among SMEs. This implies that accidents and fatalities on construction sites can be curtailed by the use of HS management plans and their implementation s on site. Also, a good welfare package for workers and government and clients supports is necessary.

Accidents prevention strategies identified by Constructionworld (2017) are; daily safety meetings, reduce the amount of night work, proper safety gear, reflective or highly-visible clothing, regular and frequent breaks, clear signage to warn of danger, introduce a warm-up or calisthenics exercise, avoid sunlight to minimize fatigue, practice defensive 
driving/parking/backing up, be aware of worker diets and encourage healthy eating. Wong et al. (2015) recommended that good occupational health and safety (OHS) practices can be improved in construction companies through Financial supports to small construction organisations to improve the OHS competence of the workers, punishing non-compliant workers and giving financial rewards to compliant workers, conduct proper safety training before engaging in any construction works, constant monitoring and appraisal of the company's' safety performance, explicit description of OHS responsibilities on each project in the contractual arrangements, and involvement of tertiary education sector in OHS training; are the possible ways of overcoming the impediments to good health and safety management practices by construction organisations.

Williams et al. (2019) submitted that appropriate preventive measures for the occurrence of accident include: management enforcing compliance with safety standards, the use of personal protective equipment (safety belts, safety nets), correct placement of ladder through proper supervision, constant training on right selection and use of equipment/tools, the correctness of design, an inspection of equipment, site discipline among workers, appropriateness in the usage of safety items, conspicuous location of warning signs, regular maintenance of tools and equipment, and reporting of accidents. In the Malaysian construction industry, Tanko et al. (2020) reported the awareness level of use of PPE is high but with a low compliance level. They recommended the provision of safety training and penalties to workers who fail to comply with PPE usage.

To maintain zero-accident conditions in the workplace, Sukamani \& Wang (2020) recommended a more focus on the safe environment in the construction industry. An upgrade of safety practices for improved workers' safety status was also advocated, and this would be achieved by the provision of adequate safety facilities, cultivating a better safety climate and safety culture, and the provision of adequate financial budgetary supports. Potential workers should select construction organisations with an acceptable positive safety disposition; this is to ensure the maintenance of satisfactory safety behaviours in the workplace (Sukamani \& Wang, 2020).

\section{RESEARCH METHODOLOGY}

This study assessed the perception of construction tradespeople regarding the health and safety practices on construction sites in Abuja, Nigeria. The objectives are; to determine the trade with the highest accident exposure, to ascertain the types of accidents and level of occurrences, to determine the causes of accidents, and to examine the possible measures of preventing accidents on construction sites. The choice of Abuja is premised on the fact that it is the capital of Nigeria, and both the public and private sector entities are undertaking a lot of new buildings and infrastructural projects regularly. Construction firms and specialist contractors, building and real estate investors, construction professionals and experts, and skilled and unskilled workers, would naturally be attracted to areas or regions with high job opportunities. The construction tradespeople were considered in this study because they are the workers that are physically and directly involved in the execution of the works and production of the finished buildings and other construction-related structures (Eze et al., 2017). Furthermore, these workers interact amongst themselves, and with materials, machinery, equipment, and tools in the course of discharging their duties. These increase their exposure to various kinds of hazards and accidents. In addition, these workers form a greater proportion of construction site workers employed by constructionbased firms (whether it is small, medium, or large organisations).

A well-structured questionnaire was adopted in the study and was administered to construction tradespeople in various active construction sites in the study area. The information gathered from the literature review was used to design the questionnaire into five sections. The first section of 
the questionnaire gathered data regarding the respondents' background information, the second section gathered data on the trades with the highest exposure to accidents. in this section, the respondents were asked to rate based on their experiences the various trade groups according to their level of exposure to accidents on construction site, using (1 low level, $2=$ moderate level, and 3 high levels). The third section garnered data on the types of construction accidents and their level of occurrence. The respondents were asked to rely on their experiences in the industry to rate the nine identified construction accident types based on their level of occurrence. The rating was based on a Likert scale of 1 to 5; with 5 being the highest scale and 1 being the lowest scale. The fourth section gathered data on the causes of accidents; the respondents were asked to rate the 21 selected causes of accidents on construction sites using a 5-point Likert scale in which (1=very low contribution; 5very high contribution). The last section obtained data on the possible measures of preventing accidents on construction sites. The respondents were asked to rate the 25 selected Measures for preventing accidents on construction sites based on their level of importance; using a 5-point Likert scale in which (1=very low importance; 5very high importance).

The stratified purposeful sampling technique was used in the administration of the questionnaire and in gathering data. Palinkas et al. (2015) identified stratified purposeful sampling as one of the types of purposive sampling methods that is suitable for identifying and expanding the range of variation and to narrow the range of variation and focus on similarities. As explained by Patton (2002), a stratified purposeful sample helps to capture key disparities rather than to identify a common core, even though; the similarities might emerge as the analysis progresses. The strata (in this case, the trade category) helped to organise the participants into homogeneous samples. The tradespeople were divided into their various trades (that is, by stratification), and their opinions on the subject purposively sampled. The target respondents were stratified using the grouping of Eze et al. (2017). These groups (strata) of construction site workers are; (1) Group 1 - Concreters/Mason/Bricklayers, (2) Group 2 - Steel benders/fixers, (3) Group 3 - Carpenters, (4) Group 4 - Services Operators (Plumbers \& Electricians), and (5) Group 5- Finishers (Tillers, Painters). It was submitted that purposive sampling allows for the sampling of groups of knowledgeable individuals and experience enough on the subject of interest, that are available and willing to participate, and are capable of communicating and sharing their experiences (Bernard, 2006). To reduce sample bias, and obtain quality data and ensure an economic survey, some criteria were set for choosing participants. The criteria are that participants must have at least 5years of working experience in the construction industry, within which they have participated in the completion of not less than 2 projects, and must be currently involved in an active site and willing to participate.

A preliminary survey revealed 28 active construction sites. The management of these project sites granted access to their sites for the survey. After a sampling period of nine weeks, 140 craftsmen, Artisans, and tradesmen (i.e. tradespeople) were sampled. The administration of the questionnaire was by the researchers and with the help of selected employees of the construction organisations working on the sites. The project managers and HR managers of the contractors and consultants on the construction sites chose these employees. The toolbox meeting periods were utilized in administering the questionnaires. In construction sites where toolbox meetings are not practiced, the break periods of the workers were utilised. This is because construction workers are not allowed to be engaged in other activities after work has started. There was no sample size upon which the 140 usable responses retrieved could be related to in order to determine the response rate. This was because there was inseperate register of construction tradespeople that met the set criteria for participation, and this made it impracticable to determine the sample population and size. 
The gathered data were analysed using frequencies, percentiles, mean analytics, Kruskal-Wallis test, and Mann-Whitney U tests. Frequencies and percentiles were used to analyse the background information of the respondents and in determining the trade with the highest accident exposure, and types of accidents on site. The mean analytics, Kruskal-Wallis test, and Mann-Whitney U tests were used to analyse the causes of accidents and possible measures for preventing accidents on construction sites. The mean analytics was used in the ranking and determination of the major variables, Kruskal-Wallis test was used to determine if there are statistically significant differences in the opinions of the five (5) groups of respondents regarding the assessed variables. Similarly, the Mann-Whitney U-Test was used to test for differences between two independent groups (i.e. to investigate which pair's view differs significantly). All analyses in this study were presented using Tables and chats. Also, the statistical package for social science (SPSS 20, IBM) was used to perform the analyses.

\subsection{Study Hypothesis and Decision Rule}

The hypotheses that guided the study are:

1. $\mathrm{H}_{1}$ : there is no significant statistical difference in the perceptions of the various groups regarding the rating of the causes of accidents

2. $\mathrm{H}_{2}$ : there is no significant statistical difference in the perceptions of the various groups regarding the rating of the measures of accident prevention on construction sites.

The decision rules for acceptance or rejection of the hypothesis are;

i. If $P$-value $\geq 0.05$, then accept the hypothesis, and

ii. If P-value $<0.05$, then reject the hypothesis.

The cut-off points for level of exposure/significance/importance modified from Morenikeji (2006) are displayed in table 1.

Table 1. The cut-off point for the rating of accidents exposure level

\begin{tabular}{ccc}
\hline $\mathrm{S} / \mathrm{Nr}$ & Percent & Decision \\
\hline 1 & $90-100$ & Very high level \\
2 & $70-89$ & High level \\
3 & $50-69$ & Moderate level \\
4 & $30-49$ & Little level \\
5 & $1-29$ & Very Little level \\
\hline
\end{tabular}

Source: Modified from Morenikeji (2006)

\subsection{Reliability Statistics and Data Normality Tests}

The reliability test for the research instrument was done using Cronbach's alpha values that revealed a range of 0.800 to 0.920 for all cases and assessed variables (see Table 2). Hair et al. (2010) suggested a Cronbach's alpha value of 0.70 and above for a good internal consistency. Based on this, the data collected were established to have a very high internal consistency and reliability, unbiased, and of high quality. The normality assumption test was further carried out using the 'Shapiro-Wilk test'. Ghasemi and Zahediasl (2012) recommended the use of the Shapiro-Wilk test for sample size fewer than 2000. A p-value of less than 0.05 was obtained for all the variables assessed (see column 7, Table 2). Based on this, the data failed the normality assumption and, categorised as non-parametric. This justifies the use of the Kruskal-Wallis test and Mann-Whitney U tests. 
Table 2. Reliability and normality tests

\begin{tabular}{|c|c|c|c|c|c|c|}
\hline \multirow{2}{*}{ Assessed variables } & \multicolumn{3}{|c|}{$\begin{array}{c}\text { Case Processing } \\
\text { Summary } \\
\end{array}$} & \multicolumn{2}{|c|}{ Reliability Statistics } & \multirow{2}{*}{$\frac{\text { Shapiro-Wilk }}{\text { P-value }}$} \\
\hline & & $\mathrm{N}$ & $\%$ & $\begin{array}{c}\text { Cronbach's } \\
\text { Alpha }\end{array}$ & $\begin{array}{l}\text { Nr. of } \\
\text { items }\end{array}$ & \\
\hline \multirow{3}{*}{$\begin{array}{l}\text { Case 1: Data on trade with the } \\
\text { highest accident exposure level }\end{array}$} & Valid & 140 & 100 & \multirow{3}{*}{0.905} & \multirow{3}{*}{5} & \multirow{3}{*}{0.000} \\
\hline & Excluded $^{\mathrm{a}}$ & 0 & 0 & & & \\
\hline & Total & 140 & 100 & & & \\
\hline \multirow{3}{*}{$\begin{array}{l}\text { Case 2: Data on the types of } \\
\text { accidents }\end{array}$} & Valid & 140 & 100 & \multirow{3}{*}{0.920} & \multirow{3}{*}{9} & \multirow{3}{*}{0.000} \\
\hline & Excluded $^{\mathrm{a}}$ & 0 & 0 & & & \\
\hline & Total & 140 & 100 & & & \\
\hline \multirow{3}{*}{$\begin{array}{l}\text { Case 3: Data on the causes of } \\
\text { accidents }\end{array}$} & Valid & 140 & 100 & \multirow{3}{*}{0.874} & \multirow{3}{*}{21} & \multirow{3}{*}{0.000} \\
\hline & Excluded $^{\mathrm{a}}$ & 0 & 0 & & & \\
\hline & Total & 140 & 100 & & & \\
\hline \multirow{3}{*}{$\begin{array}{l}\text { Case 4: Data on possible measures } \\
\text { for preventing accidents on } \\
\text { construction sites }\end{array}$} & Valid & 140 & 100 & \multirow{3}{*}{0.800} & \multirow{3}{*}{25} & \multirow{3}{*}{0.000} \\
\hline & Excluded $^{\mathrm{a}}$ & 0 & 0 & & & \\
\hline & Total & 140 & 100 & & & \\
\hline
\end{tabular}

Listwise deletion based on all variables in the procedure

\section{RESULTS AND DISCUSSION}

\subsection{Background Information of the Respondents}

From table 3, it can be seen that in terms of trade groups; 'Masons/concreters/bricklayers' are more with $32.14 \%$, this is followed by 'Finishers (painters, tilers, among others)' with $22.14 \%$, then 'carpenters' with $16.43 \%$, 'steel Benders/fixers/welders' and 'Services (mechanical \& Electrical)' are $15.9 \%$ and $14.29 \%$ respectively. This shows a fair representation of the various target groups. With regards to the nature of employment, $42.14 \%$ of the respondents are permanent staff, $30.71 \%$ are casual staff and $27.14 \%$ are contract staff. The implication of this is that there cannot be sustainable HS practices because a larger number of construction workers are not permanent staff. At the end of the project, they leave or are dispersed with their HS knowledge and experiences. Casualization and the use of temporary construction workers is one of the major practices of the Human resource management of construction organisations that impact health and safety management in the construction industry of most developing nations.

In terms of organisational type (size), $45.0 \%$ work with small construction organisations, $15.71 \%$ work with medium-sized firms, and $39.29 \%$ work with large organisations. The SMEs constitute about $60.71 \%$ of the total trade groups that participated in this study. This shows that the construction industry of Nigeria and other emerging economies are dominated by SMEs. The $39.29 \%$ for the large organisations might be high because they are usually commissioned on large projects that require a larger workforce than the SMEs. The years of experience also revealed that the majority of them have spent $11-15$ years in the construction industry with $37.14 \%$ and this is closely followed by those who have spent 5-10years in the industry with $34.29 \%$. This result with other experience range shown in Table 3 indicates that the participants are experienced enough for their responses to be relied upon. Concerning the number of the project executed, a greater proportion (49.29\%) have executed between 2-5projects, and $37.14 \%$ have taken part in 6-10 projects, $11.43 \%$ have executed $11-15$ projects and those who have taken part in 15 projects and above are just $2.14 \%$ of the total respondents. This further justifies the length of years they have spent in the industry and the quality of knowledge and experience on the key objective of this study. 
Table 3. Respondents' background information

\begin{tabular}{llcc}
\hline Variables & Classification & Freq. & \% \\
\hline Trades group & Carpenters & 23 & $16.43 \%$ \\
& Masons/concreters/bricklayers & 45 & $32.14 \%$ \\
& Finishers (painters, tilers, among others) & 31 & $22.14 \%$ \\
& Steel Benders/fixers/welders & 21 & $15.00 \%$ \\
& Services (mechanical \& Electrical) & 20 & $14.29 \%$ \\
Nature of employment & TOTAL & $\mathbf{1 4 0}$ & $\mathbf{1 0 0 . 0 0 \%}$ \\
& permanent staff & 59 & $42.14 \%$ \\
& casual staff & 43 & $30.71 \%$ \\
Organisation Type (size) & contract staff & 38 & $27.14 \%$ \\
& TOTAL & $\mathbf{1 4 0}$ & $\mathbf{1 0 0 . 0 0 \%}$ \\
& Small organisation & 63 & $45.00 \%$ \\
Number & Medium organisation & 22 & $15.71 \%$ \\
industry & Large organisation & 55 & $39.29 \%$ \\
& TOTAL & $\mathbf{1 4 0}$ & $\mathbf{1 0 0 . 0 0 \%}$ \\
& 5-10years & 48 & $34.29 \%$ \\
& 11-15yrs & 52 & $37.14 \%$ \\
& 16-20yrs & 22 & $15.71 \%$ \\
& 21-25yrs & 14 & $10.00 \%$ \\
Number of projects executed & above 25yrs & 4 & $2.86 \%$ \\
& TOTAL & $\mathbf{1 4 0}$ & $\mathbf{1 0 0 . 0 0 \%}$ \\
& 2-5 projects & 69 & $49.29 \%$ \\
& 6-10 projects & 52 & $37.14 \%$ \\
& $11-15$ projects & 16 & $11.43 \%$ \\
& Above 15 projects & 3 & $2.14 \%$ \\
& TOTAL & $\mathbf{1 4 0}$ & $\mathbf{1 0 0 . 0 0 \%}$ \\
\hline
\end{tabular}

\subsection{Trade Groups Accident Vulnerability Level}

The result of the analysis on the data regarding trade groups and their level of exposure to accidents on the construction site is shown in fig. 1, the percentage score where derived from the mean of the responses. It can be seen that the most vulnerable trade groups and their level of exposure to accidents on construction site is Group 1 - Concreters/Mason/Bricklayers with $79.3 \%$, this closely followed by Group 3 - Carpenters with $75.4 \%$, and then Group 2 - Steel benders/fixers with $71.4 \%$. These trade groups have a high level of vulnerability to construction hazards and accidents. The other two groups; Group 4 - Services Operators (Plumbers \& Electricians), and Group 5- Finishers (Tillers, Painters.) have a moderate level of accident exposure on construction site. This finding is an indication of safety in construction projects is everybody's business because it can affect all categories of the construction workforce. Furthermore, the varying level of exposure to hazards and accidents of the tradespeople shows that the content of the risk of every assignment differs from trade to trade. The result in this section is in support of the reports of (Baradan \& Usmen, 2006; Choi, 2015; Ray et al., 2015; Schneider \& Susi, 1994). 


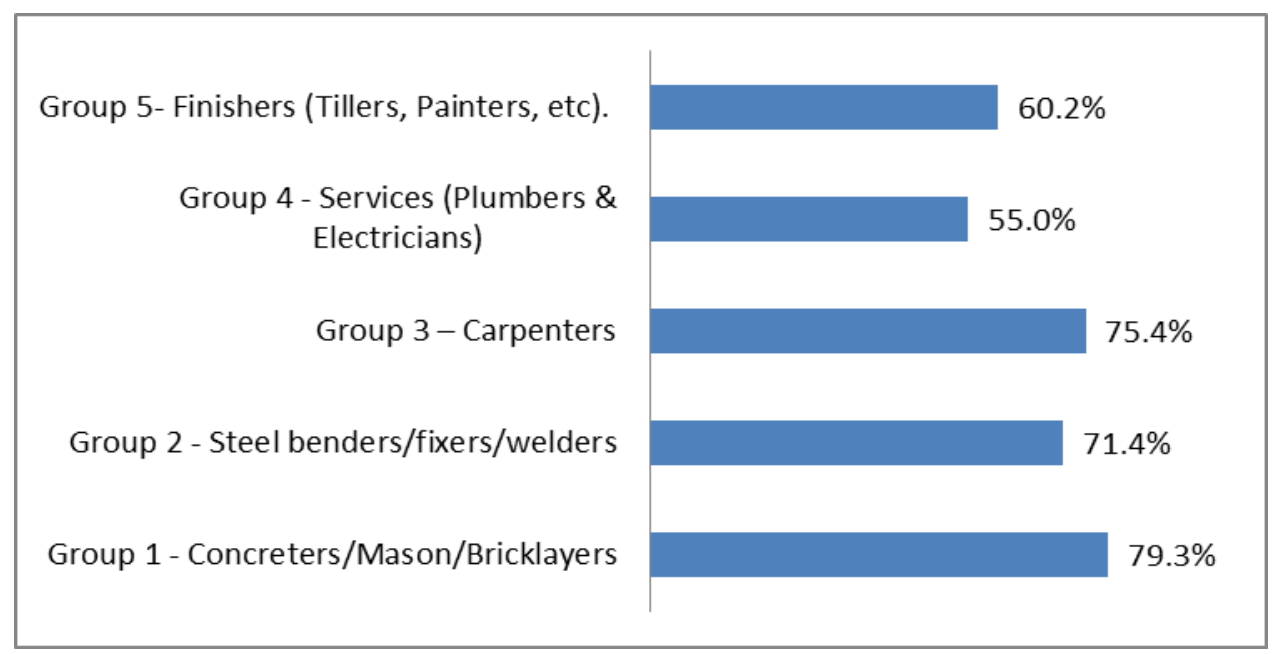

Figure 1. Trade groups accident vulnerability level

\subsection{Type of Accidents and Level of Occurrences}

The result of the analysis of the data regarding construction accident types based on their level of occurrence is shown in fig. 2 , the percentage score where derived from the mean scores. The result of the analysis revealed 3 accident types have a very high level of occurrence, and they are: Fall-related with $91.14 \%$, Slip and trip with $90.71 \%$ and then contact with objects (struck by objects) with $90.14 \%$. The other 6 types have a high level of occurrence on the construction site. However, the top of this group is Vehicle/machine-related accidents with $83.57 \%$. This finding shows that there are still a lot of inefficiencies with the operation and workings of construction organisations in Nigeria and other developing countries with HS management practices. The level of implementation of effective HS practices can be said to below. The result of this section supports the submissions of (HG.org Legal Resources, 2020; The Perecman Firm, 2014). This study also corroborates the finding of Williams et al. (2019). It was found that contact with working tools, vehicle-related, slip and trip, and falls-related accidents were the most occurring types of accidents in the construction industry.

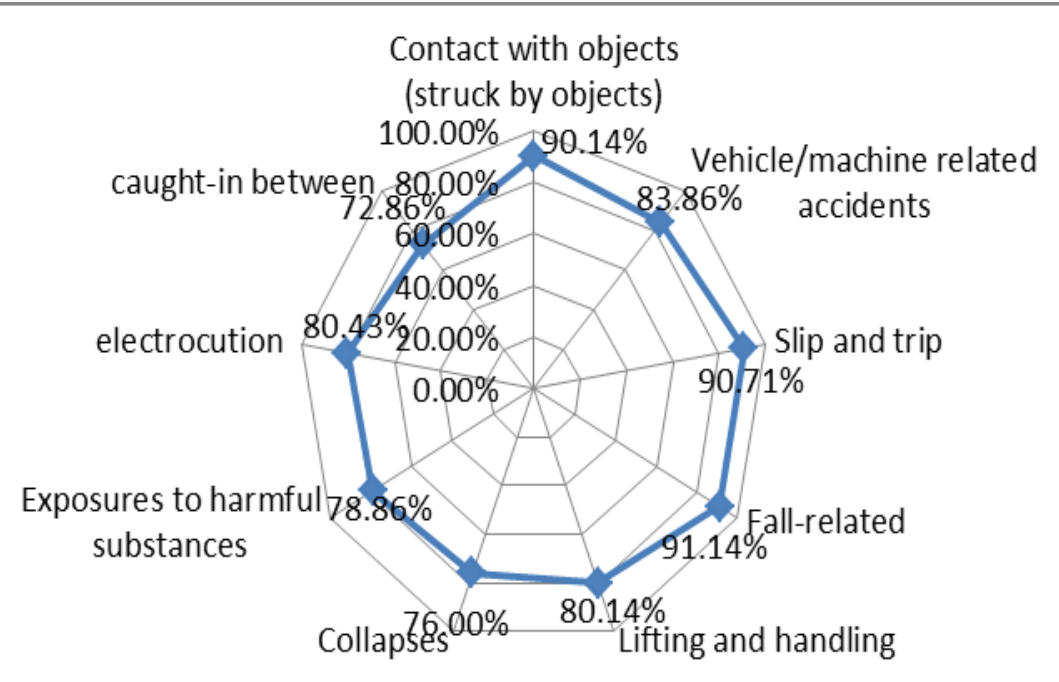

Figure 2. Type of accidents and level of occurrences 


\subsection{Causes of Accidents on Construction Sites}

The analysis of the data on the causes of accidents on the construction site is displayed in Table 4. It shows that the top ten causes of accidents are; Inadequate training (mean=4.53), drugs and alcohol (mean=4.39), Horseplay by workers (mean=4.33), Excessive working hours resulting in mental fatigue (mean=4.24), Communication issues (mean=4.21), Unsafe act, /violations/ noncompliance behaviour (mean=4.19), Unsafe working condition (mean=4.15), Poor management practices $($ mean $=4.14)$, Inadequate maintenance of tools and equipment $(\operatorname{mean}=4.08)$, and Hazardous machine operations (mean=3.98). While the least 5 causes are Lack of competency $($ mean $=3.74)$, Pressure to meet production targets $($ mean=3.73), Inadequate safety management systems (mean=3.69), Space congestion (mean=3.68), and Sun exposure (mean=3.68). It is important to stress that regardless of the relative ranking of the assessed variables, they all contribute to accidents on construction sites. This is premised on the fact that the lowest and highest mean scores are 3.68 and 4.53 respectively. This is equivalent to $73.60 \%$ and $90.60 \%$; implying that their contribution to construction site accidents ranges from high to very high. The findings of this section are in support of the findings of (Arunkumar \& Gunasekaran, 2018; Julie Bell \& Healey, 2006; Williams et al., 2019; Yusof \& Misnan, 2019; Zou et al., 2007).

Arunkumar and Gunasekaran (2018) found that the major causes of accidents on the construction site are; unsafe acts, unsafe working conditions, communication barriers, management commitment, and lack of training. The lack of training on safety management, communication issues, poor safety motivation, poor safety culture of the organisation has been reported by (Yusof \& Misnan, 2019) to be among the major causes of accidents on construction sites. According to the report of Williams et al. (2019), some of the major causes of accidents are; violation of safety standards, poor supervision of working platform installations, over speeding of vehicle, wrong selection of working tools, non-usage of personal protective equipment, improperly installed equipment, horseplay, and poor housekeeping. Zou et al. (2007) reported that accidents on-site were blamed on pressure from the construction projects, long hours spent on construction work, hazardous machine operations, and unsafe work environment.

The lack of HS knowledge and training is among the top causes of accidents on the construction site. An ill-training worker is a hazard to other workers and the project being executed. Lack of training could lead to negligence, unsafe behaviours, horseplay, taking dangerous short-cuts that could even result to rework and poor-quality work. Drugs and alcohol were found to be among the top causes of accidents on the construction site. A worker working under the influence of drugs/alcohol is a hazard to himself and others. Ordinarily, HS training and induction programmes should state explicitly educate workers on the danger of drugs and alcohol.

In order to determine if there is a significant statistical difference in the perception of the participants regarding the rating of the variables, the Kruskal-Wallis test was conducted. It was revealed that the participants have a divergent opinion on six of the variables. These variables have their p-value to be less than 0.05 significant level, and they are; Inadequate procedures, Improper use of safety items/equipment and tools, Failure to learn lessons from previous incidents, Lack of competency, and Sun exposure. These variables represent $23.81 \%$ of the 21 causes assessed. These differences in the ranting of these variables could be as a result of the differing level of knowledge and experiences of the respondents, and the level of commitment to HS practices by the various sizes of organisations sampled. $76.19 \%$ of the variables assessed have their p-value to be greater than 0.05 , thus, the respondents have a convergent view on these variables.

The overall Kruskal-Wallis Test showed a p-value of 0.088 , thus, implying that there is no significant statistical difference in the perceptions of the various groups regarding the rating of the causes of accidents. Based on these, hypothesis (H1) is accepted. 
Table 4. Causes of accidents on construction sites

\begin{tabular}{|c|c|c|c|c|c|c|}
\hline \multirow[b]{2}{*}{ Causes of accidents } & \multirow[b]{2}{*}{$\begin{array}{c}\text { Mea } \\
\mathbf{n}\end{array}$} & \multirow[b]{2}{*}{ SD } & \multirow[b]{2}{*}{$\underset{\mathbf{k}}{\operatorname{Ran}}$} & \multicolumn{3}{|c|}{ Kruskal-Wallis Test } \\
\hline & & & & $\begin{array}{c}\text { Chi- } \\
\text { squar } \\
\text { e }\end{array}$ & Sig. & $\begin{array}{c}\text { Decisio } \\
\text { n }\end{array}$ \\
\hline Excessive working hours resulting in mental fatigue & 4.24 & $\begin{array}{c}1.137 \\
2\end{array}$ & $4^{\text {th }}$ & 1.988 & 0.644 & Accept \\
\hline Horseplay by workers & 4.33 & $\begin{array}{c}0.808 \\
6\end{array}$ & $3^{\text {rd }}$ & 4.538 & 0.338 & Accept \\
\hline Hazardous machine operations & 3.98 & $\begin{array}{c}1.082 \\
7\end{array}$ & $10^{\text {th }}$ & 8.039 & 0.090 & Accept \\
\hline Unsafe working condition & 4.15 & $\begin{array}{c}1.017 \\
3\end{array}$ & $7^{\text {th }}$ & 7.907 & 0.095 & Accept \\
\hline Space congestion & 3.68 & $\begin{array}{c}1.299 \\
0\end{array}$ & $20^{\text {th }}$ & 6.714 & 0.152 & Accept \\
\hline The pressure to meet production targets & 3.73 & $\begin{array}{c}1.257 \\
2\end{array}$ & $18^{\text {th }}$ & 6.356 & 0.174 & Accept \\
\hline Inadequate safety management systems & 3.69 & $\begin{array}{c}1.268 \\
9\end{array}$ & $19^{\text {th }}$ & 4.938 & 0.308 & Accept \\
\hline Failure to learn lessons from previous incidents & 3.74 & $\begin{array}{c}1.299 \\
5\end{array}$ & $16^{\text {th }}$ & 13.473 & $\begin{array}{c}0.009 \\
*\end{array}$ & Reject \\
\hline Sun exposure & 3.68 & $\begin{array}{c}1.271 \\
0\end{array}$ & $20^{\text {th }}$ & 9.983 & $\begin{array}{c}0.041 \\
*\end{array}$ & Reject \\
\hline Unsafe act, /violations/ non-compliance behaviour & 4.19 & $\begin{array}{c}1.051 \\
9\end{array}$ & $6^{\text {th }}$ & 6.676 & 0.154 & Accept \\
\hline Improper use of safety items/equipment and tools & 3.85 & $\begin{array}{c}1.251 \\
9\end{array}$ & $14^{\text {th }}$ & 14.447 & $\begin{array}{c}0.006 \\
*\end{array}$ & Reject \\
\hline Lack of competency & 3.74 & $\begin{array}{c}1.260 \\
2\end{array}$ & $16^{\text {th }}$ & 32.194 & $\begin{array}{c}0.000 \\
*\end{array}$ & Reject \\
\hline Inadequate procedures & 3.91 & $\begin{array}{c}1.166 \\
0\end{array}$ & $12^{\text {th }}$ & 26.186 & $\begin{array}{c}0.000 \\
*\end{array}$ & Reject \\
\hline Inadequate maintenance of tools and equipment & 4.08 & $\begin{array}{c}1.112 \\
8\end{array}$ & $9^{\text {th }}$ & 2.752 & 0.600 & Accept \\
\hline Communication issues & 4.21 & $\begin{array}{c}1.007 \\
1\end{array}$ & $5^{\text {th }}$ & 9.36 & 0.053 & Accept \\
\hline Lack of management commitment & 3.97 & $\begin{array}{c}1.124 \\
9\end{array}$ & $11^{\text {th }}$ & 1.953 & 0.744 & Accept \\
\hline Ignorance of PPE (Personal Protective Equipment) & 3.88 & $\begin{array}{c}1.190 \\
3\end{array}$ & $13^{\text {th }}$ & 2.25 & 0.676 & Accept \\
\hline Poor management practices & 4.14 & $\begin{array}{c}1.035 \\
8\end{array}$ & $8^{\text {th }}$ & 2.45 & 0.654 & Accept \\
\hline Inadequate training & 4.53 & $\begin{array}{c}0.843 \\
5\end{array}$ & $1^{\text {st }}$ & 6.003 & 0.199 & Accept \\
\hline Drugs and alcohol & 4.39 & $\begin{array}{c}1.007 \\
8\end{array}$ & $2^{\text {nd }}$ & 7.207 & 0.065 & Accept \\
\hline Poor accidents reporting systems & 3.82 & $\begin{array}{c}1.374 \\
3\end{array}$ & $15^{\text {th }}$ & 9.275 & 0.055 & Accept \\
\hline
\end{tabular}

$*$ Sig. $=$ p-value $<0.05 ; \mathrm{df}=4$

Following the overall Kruskal-Wallis Test which showed a significant p-value of 0.088 , the Mann-Whitney $U$ test was conducted to determine the pair of the respondents whose view will differ significantly. From table 5, it can be seen that there is no significant statistical difference in the perception of every pair of the respondent group. 
Table 5. Mann-Whitney U test for causes of accident on construction site

\begin{tabular}{llccc}
\hline Target groups & N & Z & Sig. & Decision \\
\hline Group 1 vs Group 2 & 66 & -1.261 & 0.207 & Accept \\
Group 1 vs Group 3 & 68 & -1.741 & 0.082 & Accept \\
Group 1 vs Group 4 & 65 & -1.473 & 0.105 & Accept \\
Group 1 vs Group 5 & 76 & -0.959 & 0.338 & Accept \\
Group 2 vs Group 3 & 44 & -0.683 & 0.494 & Accept \\
Group 2 vs Group 4 & 41 & -1.873 & 0.061 & Accept \\
Group 2 vs Group 5 & 52 & -0.168 & 0.866 & Accept \\
Group 3 vs Group 4 & 43 & -1.011 & 0.312 & Accept \\
Group 3 vs Group 5 & 54 & -0.220 & 0.826 & Accept \\
Group 4 vs Group 5 & 51 & -1.319 & 0.187 & Accept \\
\hline Group 1
\end{tabular}

Group 1 - Concreters/Mason/Bricklayers; Group 2 - Steel benders/fixers; Group 3 Carpenters; Group 4 - Services Operators (Plumbers \& Electricians); Group 5- Finishers (Tillers, Painters)

\subsection{Measures for Minimising Accidents on Construction Sites}

The result of the analysis of the data on the measures for minimising accidents on construction sites revealed that the top ten measures for preventing accidents on construction sites are; rewards and penalties for defaulters (mean=4.69), the use of personal protective equipment (mean=4.62), effective communication system on-site $($ mean $=4.57)$, correct placement of ladder through proper supervision $($ mean $=4.44)$, Site discipline among workers $($ mean=4.41), Regular inspection and maintenance of tools and equipment (mean=4.32), Encouraging healthy eating and monitor workers diets (mean=4.31), Strict monitoring and enforcement of safety regulation (mean=4.23), Management commitment on HS practices (mean=4.22), and Health and safety training and induction programmes $($ mean=4.21). The least five measures for preventing accidents on construction sites are; proper workers' welfare (mean=3.94), Client commitment to bring an improvement to safety (mean=3.86), Exchanges of knowledge and experiences on HS best practices (mean=3.72), Creation and implementation of HS plans (mean=3.66), and Government supports and commitment (mean=3.46). Based on these results, the lowest and highest mean scores are 3.46 and 4.69 respectively. This is equivalent to 69.20 and $93.80 \%$, thus, this implies a moderate to very high importance/efficacy of the assessed measures. The result of this section supports the submissions of (D. O. Aghimien et al., 2019; Belayutham \& Ibrahim, 2019; Sunindijo, 2015; Williams et al., 2019).

According to Belayutham \& Ibrahim (2019), rewards and penalties for defaulters, effective communication system on-site, and health and safety training programmes were among the HS improvement strategies. Sunindijo (2015) advocated for safety training incentives and supports; to enable companies to improve on their training programmes. Tanko et al. (2020) recommended the provision of safety training and penalties to workers who fail to comply with PPE usage. Williams et al. (2019) also submitted that appropriate preventive measures for the occurrence of accidents are; management enforcing compliance with safety standards, the use of personal protective equipment, correct placement of ladder through proper supervision, constant training on right selection and use of equipment/tools, correctness of design, an inspection of equipment, site discipline among workers, appropriateness in the usage of safety items, conspicuous location of warning signs, regular maintenance of tools and equipment, and reporting of accidents.

Management commitment and support is the key to ensuring strict monitoring and enforcement, ensuring effective communications between workers and supervisors and management. 
Construction workers should also be encouraged on healthy eating and dieting, which includes informing workers on the dangers of drug and alcohol consumption.

Similarly, the Kruskal-Wallis Test conducted revealed that the respondents' view differs in six of the assessed measures. These measures are; appropriateness in the usage of safety items, efficient accident reporting systems, reducing the amount of night work, proper workers' welfare, client commitment to bring an improvement to safety, and government supports and commitment. The variables have their $\mathrm{p}$-value to be less than 0.05 significant levels. They represent about $24.0 \%$ of the 25 assessed measures. The opinion of the participants is said to be divergent on these variables. $76.0 \%$ ( 19) of the assessed variables have their $\mathrm{p}$-value to be greater than 0.05 , which implies a convergent opinion.

The overall Kruskal-Wallis Test for the 25 assessed variables showed a p-value of 0.623 , thus, implying that there is no significant statistical difference in the perceptions of the various groups regarding the rating of the measures of accident prevention on construction sites. Based on these, hypothesis (H2) is accepted.

Table 6. Measures for preventing accidents on construction sites

\begin{tabular}{|c|c|c|c|c|c|c|}
\hline \multirow[b]{2}{*}{ Accidents prevention measures } & \multirow[b]{2}{*}{ Mean } & \multirow[b]{2}{*}{ SD } & \multirow[b]{2}{*}{ Rank } & \multicolumn{3}{|c|}{ Kruskal-Wallis Test } \\
\hline & & & & $\begin{array}{l}\text { Chi- } \\
\text { square }\end{array}$ & Sig. & Decision \\
\hline Client commitment to bring an improvement to safety & 3.86 & 1.3495 & $22^{\text {nd }}$ & 12.026 & $0.017 *$ & Reject \\
\hline Health and safety training and induction programmes & 4.21 & 0.9252 & $10^{\text {th }}$ & 8.141 & 0.087 & Accept \\
\hline $\begin{array}{l}\text { Exchanges of knowledge and experiences on HS best } \\
\text { practices }\end{array}$ & 3.72 & 1.1063 & $23^{\text {rd }}$ & 7.432 & 0.115 & Accept \\
\hline Strict monitoring and enforcement of safety regulation & 4.23 & 0.9395 & $8^{\text {th }}$ & 5.521 & 0.238 & Accept \\
\hline Rewards and penalties for defaulters & 4.69 & 0.6775 & $1^{\text {st }}$ & 8.091 & 0.090 & Accept \\
\hline Effective communication system on site & 4.57 & 0.8409 & $3^{\text {rd }}$ & 7.307 & 0.075 & Accept \\
\hline Government supports and commitment & 3.46 & 1.2547 & $25^{\text {th }}$ & 40.624 & $0.000 *$ & Reject \\
\hline Creation and implementation of HS plans & 3.66 & 1.2682 & $24^{\text {th }}$ & 3.012 & 0.069 & Accept \\
\hline Proper workers' welfare & 3.94 & 1.1643 & $21^{\mathrm{st}}$ & 17.768 & $0.001 *$ & Reject \\
\hline Daily toolbox or safety meetings & 4.06 & 1.0263 & $16^{\text {th }}$ & 1.060 & 0.901 & Accept \\
\hline Reduce the amount of night work & 3.97 & 1.0522 & $20^{\text {th }}$ & 15.669 & $0.003 *$ & Reject \\
\hline Regular and frequent breaks & 4.16 & 1.0055 & $11^{\text {th }}$ & 9.022 & 0.061 & Accept \\
\hline Clear signage to warn of danger & 4.15 & 1.1375 & $12^{\text {th }}$ & 2.269 & 0.676 & Accept \\
\hline Introduce a warm-up or callisthenics exercise & 4.02 & 1.1282 & $18^{\text {th }}$ & 4.020 & 0.180 & Accept \\
\hline Avoid sunlight to minimize fatigue and glare & 4.09 & 1.1660 & $15^{\text {th }}$ & 3.954 & 0.190 & Accept \\
\hline Practice defensive driving/parking/backing up & 4.05 & 1.0271 & $17^{\text {th }}$ & 3.357 & 0.304 & Accept \\
\hline Encouraging healthy eating and monitor workers diets & 4.31 & 0.7481 & $7^{\text {th }}$ & 3.178 & 0.348 & Accept \\
\hline The use of personal protective equipment & 4.62 & 0.5427 & $2^{\text {nd }}$ & 2.469 & 0.615 & Accept \\
\hline Correct placement of the ladder through proper supervision & 4.44 & 0.8993 & $4^{\text {th }}$ & 2.147 & 0.709 & Accept \\
\hline Management commitment to HS practices & 4.22 & 1.0867 & $9^{\text {th }}$ & 1.554 & 0.817 & Accept \\
\hline Site discipline among workers & 4.41 & 0.9817 & $5^{\text {th }}$ & 1.090 & 0.922 & Accept \\
\hline Appropriateness in the usage of safety items & 4.12 & 1.1346 & $14^{\text {th }}$ & 15.070 & $0.005^{*}$ & Reject \\
\hline Regular inspection and maintenance of tools and equipment & 4.32 & 0.8755 & $6^{\text {th }}$ & 6.214 & 0.157 & Accept \\
\hline Efficient accident reporting systems & 4.01 & 1.1505 & $19^{\text {th }}$ & 14.296 & $0.006^{*}$ & Reject \\
\hline Provision of adequate safety facilities & 4.15 & 0.8726 & $12^{\text {th }}$ & 4.9880 & 0.3124 & Accept \\
\hline
\end{tabular}

$*$ Sig. $=$ p-value $<0.05 ; \mathrm{df}=4$

Following a significant p-value of 0.623 obtained for the overall Kruskal-Wallis Test, the MannWhitney $U$ test was conducted to determine the pair of the respondents whose views will differ significantly. From table 7, it can be seen that there is no significant statistical difference in the perception of every pair of the respondents, except for Group 2 vs Group 4 (Group 2 - Steel benders/fixers VS Group 4 - Services Operators (Plumbers \& Electricians)). This pair has a p- 
value of less than 0.05 , indicating a divergence of opinion between the two trade groups. This, therefore calls for further reflection and could be a basis for further investigation.

Table 7. Mann-Whitney U test for causes of accident on construction site

\begin{tabular}{llccc}
\hline Target groups & $\mathbf{N}$ & $\mathbf{Z}$ & Sig. & Decision \\
\hline Group 1 vs Group 2 & 66 & -1.505 & 0.132 & Accept \\
Group 1 vs Group 3 & 68 & 0.000 & 1.000 & Accept \\
Group 1 vs Group 4 & 65 & -1.445 & 0.148 & Accept \\
Group 1 vs Group 5 & 76 & -0.64 & 0.522 & Accept \\
Group 2 vs Group 3 & 44 & -1.296 & 0.195 & Accept \\
Group 2 vs Group 4 & 41 & -2.577 & $0.010^{*}$ & Reject \\
Group 2 vs Group 5 & 52 & -1.682 & 0.092 & Accept \\
Group 3 vs Group 4 & 43 & -1.232 & 0.218 & Accept \\
Group 3 vs Group 5 & 54 & -0.403 & 0.687 & Accept \\
Group 4 vs Group 5 & 51 & -0.542 & 0.588 & Accept \\
\hline
\end{tabular}

Group 1 - Concreters/Mason/Bricklayers; Group 2 - Steel benders/fixers; Group 3 - Carpenters; Group 4 Services Operators (Plumbers \& Electricians); Group 5- Finishers (Tillers, Painters)

\section{CONCLUSION AND RECOMMENDATIONS}

This study adopted a well-structured questionnaire and the stratified purposive sampling technique gathering data from construction tradespeople regarding the health and safety practices on construction sites within Abuja, Nigeria. The objectives were to determine the trade with the highest accident exposure, the causes of accidents, and possible measures of preventing accidents on construction sites. With a fair representation of the main trade groups from construction SMEs and large organisations, the study was able to meet its aim.

The study found that trades groups such as 'Concreters/Mason/Bricklayers', 'Carpenters', and 'Steel benders/fixers/welders', are the trades groups that are more vulnerable to hazards and accidents on construction sites. Also, Fall-related, Slip and trip, contact with objects (struck by objects) and Vehicle/machine-related accidents are the most occurring accidents types in the construction industry. The most critical causes of accidents based on tradespeople perception are; inadequate training, Drugs, and alcohol, Horseplay by workers, Excessive working hours resulting in mental fatigue, Communication issues, Unsafe act, /violations/ non-compliance behaviour, Unsafe working condition, Poor management practices, Inadequate maintenance of tools and equipment, and Hazardous machine operations. The study also found that the most important measures for preventing accidents on construction sites are; rewards and penalties for defaulters, the use of personal protective equipment, Effective communication system on-site, Correct placement of ladder through proper supervision, Site discipline among workers, Regular inspection and maintenance of tools and equipment, Encouraging healthy eating and monitor workers diets, Strict monitoring and enforcement of safety regulation, Management commitment on HS practices, and Health and safety training and induction programmes. The study concludes that there is a low level of implementation of health and safety management practices on construction projects site by construction organisations. This conclusion is premised on the very high level of occurrence of the major accident types observed in this study.

Based on the major findings, the following recommendations were made to improve health and safety management practices on the construction site. These will ensure the safety of the critical workers like the tradespeople and ensure timely and cost-effective delivery of the project with the required quality specification.

1. Periodic HS compliance rewards to the most HS compliant workers or trade groups. This will encourage others to emulate their pairs. Also, the introduction of penalties or punishment 
to HS deviant workers or trades groups. This will serve as a deterrent and control to those workers who have normalised deviant behaviours with regards to health and safety practices.

2. The management of construction project site should up their game and commit more resources and efforts to ensure that HS is taken seriously by all and sundry. This entails strict monitoring and enforcement of safety regulation in terms of use of PPE, proper housekeeping, an inspection of tools/equipment, and inspection of working platforms above chest level (e.g. ladders and scaffolds), proper supervision of workers to avoid horse plays during working hours and within working areas. Health and safety training and induction programmes should be taken seriously and a system of check should be provided to ensure that every employee passed the primary induction tests and are well trained on the issues of HS.

3. The introduction of weekly alcohol and drug test to ensure that workers are in their right frame of mind at all times. This will help curtain accidents from slip and trip, falls, and vehicle-rated accidents.

4. There should be better communication and exchange of information across the site management and organisational hierarchy. Also, workers should be encouraged on healthy eating and to ensure a balanced diet at all times.

5. The length of overtime should be reduced and a system of the shift should be put in place to avoid some workers working overtime which predisposes them to hazards. More lighting should be provided where night work is allowed, and those workers on night shift should also have regular safety toolbox meetings, and sometimes safety drills are organised to awaken their consciousness to safety issues.

This study sampled only construction tradespeople who have been identified as very critical to success or order wise of a construction project delivery. The failure of the set of workers means that construction projects will fail in terms of time cost and quality, these make their health and safety, and mental well-being a key ingredient to the delivery of projects.

This study adds to the available body of knowledge on health and safety practices in the construction industry. The study will assist the management of construction organisations in coming up with the most suitable accident prevention measures to implement their projects. Also, the pricing of the Health and Safety section of the bill of quantities will improve as this study has identified the major causes and prevention measures that would be integrated into the buildingup of HS rates. Also when the findings of this study are communicated to construction field workers, their safety consciousness would improve because they would have seen the major causes of accidents, their exposure level, and the frequency with which these accident types occur. However, care should be exercised when generalising the major findings of this study in other regions or countries. This is because the study is limited by geographical boundary and sample size. Therefore, a similar study that would consider a larger sample size could be carried out in other states or countries, or regions so that results could be compared. This is because HS practices and implementation differ from country to country and from company to company. Also, requiring investigation is the contribution of construction tradespeople health and safety deviances could impact the project time, cost and quality, and the organisation at large.

\section{REFERENCES}

Abas, N. H., Jalani, A. F. A., \& Affandi, H. M. (2020). Construction stakeholders' perceptions of occupational safety and health risks in Malaysia. International Journal of Sustainable Construction Engineering and Technology, 11(1), 300-311. https://doi.org/10.30880/ijscet.2020.11.01.029 
Afolabi, A. O., Ojelabi, R. A., Omuh, I., Tunji-Olayeni, P., \& Adeyemi, M. (2018). Critical success factors influencing productivity of construction artisans in the building industry. International Journal of Mechanical Engineering and Technology, 9(8), 858-867.

Aghimien, D., Aigbavboa, C., Thwala, G., \& Thwala, W. (2019). Critical Drivers for Health and Safety Management among SMEs in the Eswatini Construction Industry. IOP Conference Series: Materials Science and Engineering, 640(1). https://doi.org/10.1088/1757899X/640/1/012005

Aghimien, D. O., Aigbavboa, C., Ngcobo, N., \& Thwala, W. D. (2019). Challenges of Sustainable Construction: A Study of Educational Buildings in Nigeria. 13th Built Environment Conference.

Agyekum, K., Simons, B., \& Botchway, S. Y. (2018). Factors influencing the performance of safety programmes in the Ghanaian construction industry. Acta Structilia, 25(2), 39-68. https://doi.org/10.18820/24150487/as25i2.2

Ali, H., Azimah Chew Abdullah, nor, \& Subramaniam, C. (2009). Management practice in safety culture and its influence on workplace injury: An industrial study in Malaysia. Disaster Prevention and Management: An International Journal, 18(5), 470-477. https://doi.org/10.1108/09653560911003660

Alinaitwe, H., Mwakali, J. ., \& Hansson, B. (2007). Analysis of Accidents on Building Construction Sites Reported in Uganda during 2001 - 2005. Proceedings of the CIB World Building Congress 2007, 1208-1221. https://www.irbnet.de/daten/iconda/CIB4931.pdf

Arunkumar, K., \& Gunasekaran, J. (2018). Causes and effects of accidents on construction site. International Journal of Engineering Science and Computing, 8(6), 18102-18110.

Baradan, S., \& Usmen, M. A. (2006). Comparative Injury and Fatality Risk Analysis of Building Trades. Journal of Construction Engineering and Management, 132(5), 533-539. https://doi.org/10.1061/(asce)0733-9364(2006)132:5(533)

Belayutham, S., \& Ibrahim, C. K. I. C. (2019). Barriers and strategies for better safety practices: The case of construction SMEs in Malaysia. Construction Economics and Building, 19(1). https://doi.org/10.5130/AJCEB.v19i1.6331

Bernard, H. R. (2006). Research Methods in Anthropology: Qualitative and Quantitative Approaches.

https://books.google.co.id/books/about/Research_Methods_in_Anthropology.html?id=LvF -afWmvlkC\&redir_esc $=y$

Chen, W. T., Tsai, I. C., Merrett, H. C., Lu, S. T., Lee, Y. I., You, J. K., \& Mortis, L. (2020). Construction safety success factors: A Taiwanese case study. Sustainability (Switzerland), 12(16). https://doi.org/10.3390/SU12166326

Choi, S. D. (2015). Aging Workers and Trade-Related Injuries in the US Construction Industry. Safety and Health at Work, 6(2), 151-155. https://doi.org/10.1016/j.shaw.2015.02.002

Choudhry, R. M., Fang, D., \& Ahmed, S. M. (2008). Safety management in construction: Best practices in Hong Kong. Journal of Professional Issues in Engineering Education and Practice, 134(1), 20-32. https://doi.org/10.1061/(ASCE)1052-3928(2008)134:1(20)

Constructionworld. (2017). Top 10 Tips for Preventing Accidents on Construction Sites. http://www.constructionworld.org/top-10-tips-preventing-accidents-construction-sites/

Eze, E., Seghosime, R., Eyong, O., \& Loya, O. (2017). Assessment of materials waste in the construction industry: A view of Construction Operatives, Tradesmen and Artisans in Nigeria. The International Journal of Engineering and Science, 06(04), 32-47. https://doi.org/10.9790/1813-0604013247

Ghasemi, A., \& Zahediasl, S. (2012). Normality tests for statistical analysis: A guide for nonstatisticians. International Journal of Endocrinology and Metabolism, 10(2), 486-489. https://doi.org/10.5812/ijem.3505

Hair, J. F., Black, W. C., Babin, B. J., \& Anderson, R. E. (2010). Multivariate Data Analysis. In 
Vectors. https://doi.org/10.1016/j.ijpharm.2011.02.019

Hasle, P., \& Limborg, H. J. (2006). A review of the literature on preventive occupational health and safety activities in small enterprises. Industrial Health, 44(1), 6-12. https://doi.org/10.2486/indhealth.44.6

HG.org Legal Resources. (2020). Common Causes of Construction Site Accidents. https://www.hg.org/legal-articles/common-causes-of-construction-site-accidents-27703

Idoro, G. I. (2008). Health and safety management efforts as correlates of performance in the Nigerian construction industry. Journal of Civil Engineering and Management, 14(4), 277285. https://doi.org/10.3846/1392-3730.2008.14.27

Ismail, Z., Doostdar, S., \& Harun, Z. (2012). Factors influencing the implementation of a safety management system for construction sites. Safety Science, 50(3), 418-423. https://doi.org/10.1016/j.ssci.2011.10.001

Julie Bell, \& Healey, N. (2006). The Causes of Major Hazard Incidents and How to Improve Risk Control and Health and Safety Management: A Review of the Existing Literature.

Khosravi, Y., Asilian-Mahabadi, H., Hajizadeh, E., Hassanzadeh-Rangi, N., Bastani, H., \& Behzadan, A. H. (2014). Factors influencing unsafe behaviors and accidents on construction sites: A review. International Journal of Occupational Safety and Ergonomics, 20(1), 111125. https://doi.org/10.1080/10803548.2014.11077023

Kirwan, B. (1998). Safety Management Assessment and Task Analysis-A Missing Link? In Safety Management (pp. 67-92). Elsevier. https://doi.org/10.1016/b978-008043075$1 / 50005-4$

Kukoyi, P. O., \& Smallwood, J. J. (2017). A Qualitative Study of Health and Safety (H\&amp;S) Construction Practices in Lagos. Journal of Construction Business and Management (JCBM), 1(1), 1-7. http://journals.uct.ac.za/index.php/jcbm

Lingard, H., Wakefield, R., \& Blismas., N. (2013). If you cannot measure it, you cannot improve it: Measuring health and safety performance in the construction industry. The 19th Triennial CIB World Building Congress.

Mohammed, K., Khan, I., Suguna, K., \& Raghunath, P. N. (2015). Factor Analysis on Safety Management in Construction Projects. In Asian Journal of Applied Sciences (Vol. 3, Issue 4). www.ajouronline.com

Odeyinka, H. A., Akindele, A. A., \& Oladapo, O. (2006). Assessing risk impacts on construction cost. In E. Sivyer (Ed.), The construction and building research conference. The Royal Institution of Chartered Surveyors.

Okoye, P. U. (2018). Occupational health and safety risk levels of building construction trades in Nigeria. Construction Economics and Building, 18(2), 92-109. https://doi.org/10.5130/AJCEB.v18i2.5882

Palinkas, L. A., Horwitz, S. M., Green, C. A., Wisdom, J. P., Duan, N., \& Hoagwood, K. (2015). Purposeful Sampling for Qualitative Data Collection and Analysis in Mixed Method Implementation Research. Administration and Policy in Mental Health and Mental Health Services Research, 42(5), 533-544. https://doi.org/10.1007/s10488-013-0528-y

Patton, M. Q. (2002). Qualitative research and evaluation methods. Thousand Oaks. Cal.: Sage Publications.

Ray, P. K., Parida, R., \& Saha, E. (2015). Status Survey of Occupational Risk Factors of Manual Material Handling Tasks at a Construction Site in India. Procedia Manufacturing, 3, 65796586. https://doi.org/10.1016/j.promfg.2015.07.279

Schneider, S., \& Susi, P. (1994). Ergonomics and construction: A review of potential hazards in new construction. American Industrial Hygiene Association Journal, 55(7), 635-649. https://doi.org/10.1080/15428119491018727

Sukamani, D., \& Wang, J. (2020). Prospective safety performance in construction industries in Nepal. Jordan Journal of Civil Engineering, 14(4), 457-475. 
Sunindijo, R. Y. (2015). Improving safety among small organisations in the construction industry: Key barriers and improvement strategies. Procedia Engineering, 125, 109-116. https://doi.org/10.1016/j.proeng.2015.11.017

Szóstak, M. (2019). Analysis of occupational accidents in the construction industry with regards to selected time parameters. Open Engineering, 9(1), 312-320. https://doi.org/10.1515/eng2019-0027

Tanko, B. L., Ting, L. C., \& Idiake, J. E. (2020). Compliance with the Use of Personal Protective Equipment (PPE) on Construction Sites in Johor, Malaysia. International Journal of Real Estate Studies, 14(1), 123-138.

The Perecman Firm. (2014). What are the Causes of Accident on Construction Site? https://www.perecman.com/blog/2014/april/what-are-the-causes-of-accident-onconstruction-/

Tunji-Olayeni, P. F., Mosaku, T. O., Oyeyipo, O. O., \& Afolabi, A. O. (2018). Sustainability strategies in the construction industry: Implications on Green Growth in Nigeria. IOP Conference Series: Earth and Environmental Science, 146(1). https://doi.org/10.1088/1755$1315 / 146 / 1 / 012004$

Udo, U. E., Usip, E. E., \& Asuquo, C. F. (2016). Effect of Lack of Adequate Attention to Safety Measures on Construction Sites in Akwa Ibom State, Nigeria. Journal of Earth Sciences and Geotechnical Engineering, 6(1), 113-121. http://www.scienpress.com/Upload/GEO/Vol 6_1_8.pdf

Ugulu, R. A., Arewa, A., \& Allen, S. (2019). Project-specific constraints influencing productivity of tradespeople in the Nigerian construction industry. Built Environment Project and Asset Management, 10(1), 94-109. https://doi.org/10.1108/BEPAM-10-2018-0124

Umeokafor, N., Umeadi, B., \& Jones, K. (2014). Compliance with occupational safety and health regulation: A review of Nigeria's construction industry. Nternational Conference on Infrastructure Development in Africa.

Williams, O. S., Hamid, R. A., \& Misnan, M. S. (2019). Causes of building construction related accident in the south-western states of Nigeria. International Journal of Built Environment and Sustainability, 6(1), 14-22. https://doi.org/10.11113/ijbes.v6.n1.313

Wong, J., Gray, J., \& Sadiqi, Z. (2015). Barriers to Good Occupational Health \& Safety (OHS) Practices by Small Construction Firms. NICMAR Journal of Construction Management, 1, 55-66.

Yusof, N., \& Misnan, M. S. (2019). Restriction Factors To Implement Safety Practices in Small Grade Contractors. International Journal of Built Environment and Sustainability, 6(1-2), 15-21. https://doi.org/10.11113/ijbes.v6.n1-2.378

Zhou, Z., Irizarry, J., \& Li, Q. (2013). Applying advanced technology to improve safety management in the construction industry: a literature review. Construction Management and Economics, 31(6), 606-622. https://doi.org/10.1080/01446193.2013.798423

Zou, P. X. W., Zhang, G., \& Wang, J. (2007). Understanding the key risks in construction projects in China. International Journal of Project Management, 25(6), 601-614. https://doi.org/10.1016/j.ijproman.2007.03.001 